\title{
Associations between adolescents' prosocial experiences and mental health during the COVID-19 pandemic
}

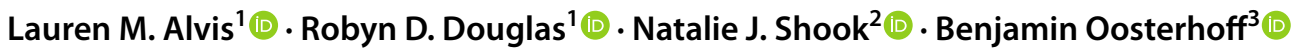

Accepted: 23 December 2021

(c) The Author(s), under exclusive licence to Springer Science+Business Media, LLC, part of Springer Nature 2022

\begin{abstract}
Natural disasters and times of crisis, such as the COVID-19 pandemic, are extremely stressful events, with severe mental health consequences. However, such events also provide opportunities for prosocial support between citizens, which may be related to mental health symptoms and interpersonal needs. We examined adolescents' prosocial experiences as both actors and recipients during the early stages of the COVID-19 pandemic and assessed whether these experiences were associated with indicators of mental health. Adolescents $\left(N=426 ; 78 \%\right.$ female) aged 13 to 20 years $\left(M_{\text {age }}=16.43, S D=1.10 ; 63.6 \%\right.$ White, 12.9\% Hispanic/Latinx, 8.5\% Asian, 4.2\% Black, 2.8\% Native American) were recruited across the US in early April of 2020. Participants reported on their COVID-19 prosocial experiences (helping others, receiving help) and mental health (depressive symptoms, anxiety symptoms, burdensomeness, belongingness). Multiple regression models indicated greater engagement in COVID-19 prosocial behavior was associated with greater anxiety symptoms and greater burdensomeness. Receiving more COVID-19 help was associated with lower depressive symptoms and higher belongingness. Findings highlight the importance of furthering our understanding of the nuanced connections between prosocial experiences and adolescents' mental health to help inform post-pandemic recovery and relief efforts.
\end{abstract}

Keywords COVID-19 $\cdot$ Adolescence $\cdot$ Prosocial behavior $\cdot$ Mental health

The novel 2019 coronavirus disease (COVID-19) was declared a pandemic on March 11, 2020 and a US national emergency on March 13, 2020 (World Health Organization [WHO], 2020). The outbreak was first revealed in late December 2019 in the city of Wuhan, Hubei Province, China and has since spread globally. By the end of April, 2020, there were over 3,018,952 confirmed cases worldwide, and over 983,457 confirmed cases in the United States (CDC, 2020; WHO, 2020). Like many natural disasters (Brooks et al., 2020; Rodriguez et al., 2006), the COVID-19 pandemic has produced several negative social, economic, and health consequences for youth, including social isolation,

Benjamin Oosterhoff

Benjamin.oosterhoff@montana.edu

1 The Hackett Center for Mental Health, P.O. Box 130059, Houston, TX 77057, USA

2 School of Nursing, University of Connecticut, Storrs Hall, Room 113B. 231 Glenbrook Road, Unit 4026, Storrs, CT 06269, USA

3 Department of Psychology, Montana State University, P.O. Box 173440, Bozeman, MT 59717-3440, USA racial discrimination, increased family financial strain, elevated mental health symptoms, and engagement in antisocial behaviors, such as hoarding (Cao et al., 2020; Oosterhoff \& Palmer, 2020; Wang et al., 2020). However, natural disasters also provide opportunities for youth to help—and be helped by-others in their community (Kaniasty \& Norris, 2004; Reissman et al., 2006). Engaging in prosocial action either as an actor or recipient in response to a collective crisis is theorized to facilitate coping and healing (Bokszczanin, 2012). Understanding connections between pandemicrelated prosocial experiences and mental health may be especially important during adolescence, which represents a developmentally sensitive period of time when youth are at risk for many mental health disorders (Lee et al., 2014).

Relational developmental systems (RDS) metatheory posits that development is the result of dynamic person $\leftarrow \rightarrow$ environment relations and that all youth have the potential for positive adaptation in the face of adversity, particularly when youths' developmental needs and strengths align with available ecological assets (i.e., social resources that foster positive youth development; Eccles \& Gootman, 2002; Overton, 2015). The COVID-19 pandemic represents 
a unique context that has shaped the nature of youths' interactions with their environment; adolescents' response to the pandemic with regard to helping others or receiving help may serve as an important ecological asset that has the potential to promote or hinder youths' mental health during this time of collective crisis. The goal of this study was to examine associations between adolescents' prosocial experiences and their mental health (anxiety symptoms, depressive symptoms, interpersonal needs) during the early stages of the COVID-19 pandemic.

\section{Adolescent Mental Health During Times of Crisis}

Adolescence is a period marked by increased risk for the development of many psychiatric disorders, such as anxiety and depression (Merikangas et al., 2010). Hormonal and neurobiological changes during adolescence coalesce with heightened emotional reactivity and the ongoing development of coping strategies (Spear, 2010). Simultaneously, adolescence is marked by the increased prioritization of peer relationships and a greater reliance on peer support (Furman $\&$ Buhrmester, 1985). Peers contribute to youths' mental health by promoting a sense of belonging and reducing a sense of burdensomeness on others (Joiner, 2007; Smetana et al., 2006). According to Joiner's (2007) interpersonalpsychological theory of suicidal behavior, the simultaneous presence of an unmet need to belong (i.e., thwarted belongingness) and feelings that one is a burden on close others (i.e., burdensomeness) can result in suicidal ideation (Joiner Jr. et al., 2002). During the COVID-19 pandemic, government regulations and social policies seeking to limit the spread of the disease had an unprecedented impact on multiple levels of adolescents' developmental contexts. School closures, social distancing guidelines, and quarantining greatly decreased in-person time spent with peers, thereby limiting an important source of social support. Heightened stress due to the physical threat of the pandemic combined with limited peer interactions may place adolescents at an elevated risk for the negative mental health effects of the pandemic (Dodd et al., 2019; Oosterhoff et al., 2020; Xie et al., 2020; Zhou et al., 2020).

\section{Prosocial Behavior During Times of Crisis}

Despite their negative impact, natural disasters and other times of crisis also provide youth with important opportunities. Adolescents often engage in prosocial behaviors during times of crisis by supporting one another, helping those in need, and preserving social functioning (Kaniasty \& Norris, 2009; Reissman et al., 2006). For instance, shortly after Hurricane Katrina, many citizens donated funds to victims, volunteered to distribute supplies, and participated in search and rescue teams (Avdeyeva et al., 2006; Rodriguez et al., 2006; Vollhardt, 2009). Clinical psychologists have referred to prosocial responses to shared experiences of trauma or crises as altruism born of suffering (Staub \& Vollhardt, 2008; Vollhardt, 2009). Shared experiences of trauma can produce perceptions of common fate and interdependence among victims of similar suffering, which can generate motivation to help each other overcome the suffering together. The COVID-19 pandemic represents one period of heightened collective stress that may provide opportunities for young people to act prosocially and benefit from the prosocial actions of others. During the early stages of the COVID-19 pandemic, media reports indicated an increase in prosocial action, including charitable donations, volunteers to grocery shop for those at risk, and volunteers producing personal protective equipment, such as facemasks (Vergin, 2020; Watson, 2020). As COVID-19 symptoms appear less severe among young people (Ludvigsson, 2020), adolescents may be willing to engage in a variety of different prosocial behaviors during this time to help others that may be at greater risk. However, research has yet to examine the extent to which adolescents may give - or receive - various forms of pandemic-related help.

\section{Prosocial Experiences and Adolescent Mental Health}

Prosocial experiences in response to natural disasters may provide benefits or social resources that align with youths' developmental needs, and therefore can be beneficial for mental health (Penner et al., 2005, for a review). For example, prosocial behavior serves as an opportunity for youth to make social connections and feel a sense of purpose and meaning during the pandemic, which may buffer against mental illness and help satisfy their interpersonal needs. In general, benefitting others through prosocial acts is associated with lower depression and anxiety (Haroz et al., 2013; Nantel-Vivier et al., 2014; Schwartz et al., 2003) and greater feelings of belongingness and lower feelings of burdensomeness (Devi et al., 2017; Oosterhoff et al., 2019; Gagné, 2003). Greater prosocial behavior during a shared trauma (e.g., the Holocaust) is related to greater psychological wellbeing after the trauma (Kahana et al., 1988), and time spent volunteering in post-disaster relief efforts is associated with increased feelings of belongingness and decreased feelings of burdensomeness (Gordon et al., 2011). Further, research and theory on social support indicates both giving and receiving support is beneficial to individuals' mental health in the context of a natural disaster or shared trauma (Kaniasty, 2012; Shakespeare-Finch \& Green, 2013; Shang 
et al., 2019). Prosocial experiences as the actor or recipient provide individuals with important intra- and interpersonal benefits that may promote mental health during times of stress.

Together, past research suggests that helping others is generally associated with better mental health. However, most of this research has been conducted with adults and less research has examined how prosocial action is connected with mental health among adolescents in the context of a global pandemic. Further, the majority of past research has focused on the psychological benefits of prosocial actors. Motivations to engage in prosocial behavior during times of stress often concern the desire to improve the well-being of others (Oosterhoff et al., 2020), suggesting that youth believe prosocial actions improve the beneficiary's welfare. Thus, receiving prosocial support from others may be an additional prosocial experience that has implications for mental health. Although studies have yet to explore adolescents' experiences receiving pandemic-related help, a large body of evidence indicates that adolescents in peer relationships characterized by warmth and support have lower rates of anxiety, depression, and suicidal ideation (Colarossi \& Eccles, 2003; Kerr et al., 2006; LaGreca \& Lopez, 1998). Receiving prosocial support during a shared crisis may help youth cope with stressful circumstances, bolster a sense of belonging, and alleviate burdensomeness, thereby reducing post-disaster risk for mental illness (Joiner, 2007). Examining connections between COVID-19 prosocial experiences-including being a prosocial actor and recipient_and mental health during adolescence is an important first step toward advancing our understanding of how variability in pandemic-related experiences may be negatively or positively affecting youth.

\section{The Current Study}

The primary aim of this research was to describe adolescents' prosocial experiences during the COVID-19 pandemic and examine how being the actor or recipient of COVID19 specific prosocial acts was related to adolescents' mental health (depressive symptoms, anxiety symptoms, burdensomeness, belongingness). Consistent with conceptualizing prosocial interactions as an ecological asset in the context of a pandemic, we hypothesized that greater experience with prosocial action (both as an actor and recipient) would be associated with lower depressive symptoms, lower anxiety symptoms, lower burdensomeness, and higher belongingness. Past research has found substantial heterogeneity in youths' negative natural disaster experiences (Cao et al., 2020; Dodd et al., 2019), as well as age, gender, race/ethnicity, and socioeconomic differences in adolescents' mental health symptoms (Kessler et al., 2009). We therefore accounted for variability in adolescents' negative COVID-19 experiences and a variety of demographic characteristics to isolate links between prosocial experiences and mental health.

\section{Method}

\section{Participants and Procedures}

The survey was completed by 426 adolescents residing in the United States between the ages of 13-20 years $(M=16.43$, $S D=1.10)$. The sample was primarily 11 th $(29.6 \%)$ and 12 th $(32.6 \%)$ graders with some 9 th graders $(14.3 \%)$, 10th graders $(22.2 \%)$, and college students $(1.2 \%)$. The sample was composed of more females $(78.8 \%)$ than males $(18.0 \%)$ with $3.2 \%$ identifying as non-binary. The sample was primarily White/Caucasian (78.1\%), followed by Hispanic/Latino (15.9\%), Asian American/Pacific Islander (9.7\%), African American/Black (5.8\%), American Indian/Alaskan Native (3.7\%), and other (4.8\%). Participants could select multiple racial/ethnic categories and $15.6 \%$ endorsed two or more categories. As a proxy for family financial strain (Galinsky, 1999), youth were asked whether their families had: enough money to buy almost anything they wanted (4.8\%), no problem buying the things they need and can also sometimes buy special things $(51.7 \%)$, just enough money for the things they need $(34.2 \%)$, or a hard time buying the things they need $(9.2 \%)$. Seventy percent of youth indicated they had at least one parent graduate from college.

Data were collected at 7:00 PM on April 12th through 5:00 PM Mountain Time on April 13th of 2020, one month after COVID-19 was declared a national emergency in the United States. The study was selectively advertised on Facebook and Instagram to youth between the ages of 13- and 18-years using Facebooks' audience application. To limit selection bias, multiple advertisements were used and a general study description was provided concerning interest in psychological research more broadly. Participants selfselected into the study and completed a 10-min survey. This method of recruitment is consistent with past research (e.g., Oosterhoff et al., 2021; Oosterhoff \& Palmer, 2020) and was chosen for multiple reasons. First, the social implications of COVID-19 were quickly evolving during the time of recruitment, thus requiring data to be collected in a very short period of time. Second, state-mandated high school closures made community-based data collection unfeasible. Third, many online data collection platforms (e.g., Mturk) do not provide access to adolescent participants, thus limiting access to national samples. This study involved no more than minimal risk and thus a waiver of parental permission was granted. Upon survey completion, participants were given a link to a letter explaining their participation in the study and asked to provide this letter to their parents. Parents were given the option to have their teen's data removed from 
the study by contacting the research team and indicating the time that survey was completed. Those who completed the initial survey were entered into a drawing for a $\$ 50$ Amazon gift card. This study was approved by the Institutional Review Board at the last author's institution.

Data Verification and Quality Checks Demographic information was verified by recontacting a subsection of participants and cross-referencing multiple reports of demographic profiles. A subsection of participants (20\%) were randomly selected and emailed a short demographic questionnaire asking them to report their age, gender, and race/ ethnicity. Results of this screening indicated a high degree of agreement between the two demographic reports. Data were screened to ensure that participants did not take the survey multiple times by identifying duplicates in Internet Protocol (IP) addresses (see Kennedy et al., 2018). Per recommendations by Kennedy et al. (2018), data quality was also assessed by evaluating responses to open-ended questions unrelated to this study. Data 'straight lining' was tested to identify undifferentiated response patterns using the 'careless' package in R (Yentes \& Wilhelm, 2018). These screening procedures resulted in the omission of five participants.

\section{Measures}

COVID-19 Prosocial Experiences A multi-phase process was used to assess adolescents' experiences with prosocial action in response to the COVID-19 pandemic. In the first phase, free-response data were collected from an independent sample of adolescents $(n=648)$ in which youth were asked to describe the most significant experience with helping others due to COVID-19 and with being helped by others due to COVID-19 that they had in the past 7 days. These two free-response questions on COVID-19 prosocial experiences were preceded by two quantitative items that primed youth to think about times they helped other people with any struggles they may have had due to COVID-19 and have been helped by other people with any struggles they personally have faced due to COVID-19. Free-response data were collected the week prior (April 5th and 6th, 2020) to the current study. Adolescents' responses were thematically coded using two independent raters who coded all responses. Coding discrepancies were addressed through discussion until a unanimous decision was made. The most common types of prosocial acts identified across responses to both freeresponse questions were then used to develop a quantitative measure of COVID-19 prosocial experiences. (See the Supplemental Material for greater details concerning sample description and procedure.)

Based on themes extracted from the free-response data in the first phase, eight items were developed to measure how often participants engaged in COVID-19 prosocial acts (as the actor) in the past 7 days $(\alpha=.71)$ and four items were developed to measure how often participants received help from others because of COVID-19 in the past 7 days. Given the few number of items used to assess receiving prosocial behavior, corrected item-total correlations were also used to assess the internal consistency of receiving help from others, which were all in the acceptable range $(r \mathrm{~s}=.32$ to .38; Nunnally \& Bernstein, 1994). Items are described in Fig. 1 and the full measure is available in the Supplemental Materials. Responses for both measures were given on a scale from 1 (not at all) to 5 (very often). Mean scores were calculated with higher values indicating greater engagement in prosocial behavior and greater receipt of help from others, respectively.

Anxiety Symptoms Anxiety symptoms were assessed using the short fixed-form 8-item Patient-Reported Outcomes
Fig. 1 Frequency Distribution of Adolescents' COVID-19 Prosocial Experiences. Total $\mathrm{N}=467$. Items A1-A8 measured youths experiences as the actor in prosocial acts and items R1-R4 measured experiences as the recipient in prosocial acts. When applicable, item wording specified "... because of COVID-19." See Supplemental Materials for full item wording

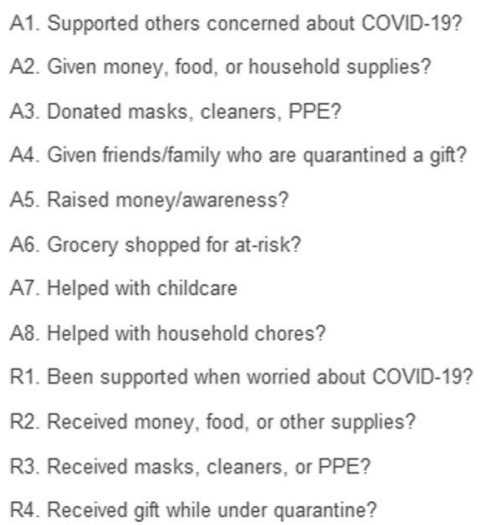

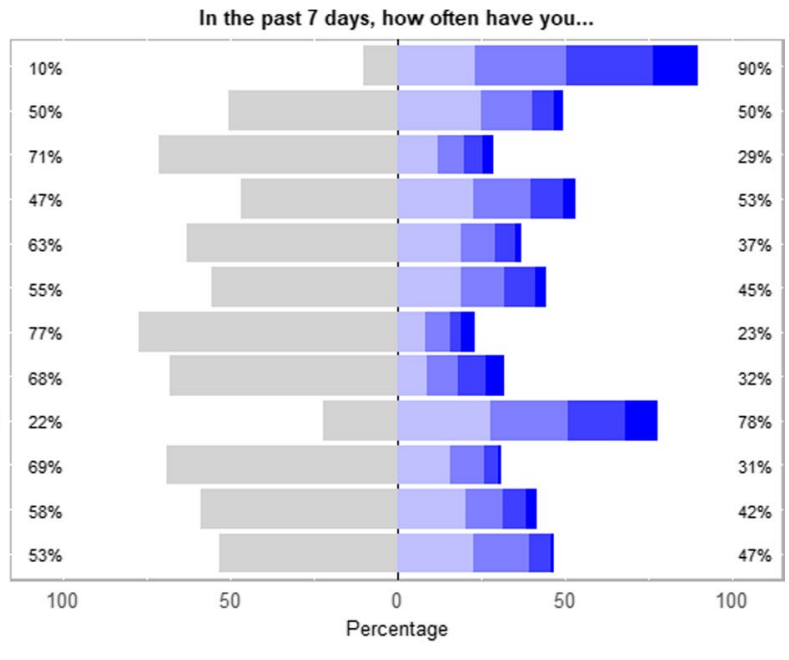

Not at All $\square$ A Little $\square$ Somewhat $\square$ Often $\square$ Very Often 
Measurement Information System (PROMIS) anxiety scale $(\alpha=.94$; Quinn et al., 2014). Youth rated their agreement with items (e.g., "In the past 7 days, I felt nervous.") on a scale from 1 (never) to 5 (almost always). Mean scores were calculated with higher values indicating greater anxiety symptoms.

Depressive Symptoms Depressive symptoms were assessed using the short fixed-form 8-item PROMIS depression scale $(\alpha=.93$; Quinn et al., 2014). Youth rated their agreement with items (e.g., "In the past 7 days, I felt sad.") on a scale from 1 (never) to 5 (almost always). Mean scores were calculated with higher values indicating greater depressive symptoms.

Belongingness Belongingness was measured with three items $(\alpha=.82)$ adapted from the Interpersonal Needs Questionnaire (Joiner, 2007). Participants rated the extent to which they belong, that other people care about them, and they felt like they have many caring and supportive friends on a scale from 1 (not at all) to 7 (extremely). Mean scores were calculated with higher values indicating greater feelings of belongingness.

Burdensomeness Burdensomeness was measured with two items $(r=.65)$ adapted from the Interpersonal Needs Questionnaire (Joiner, 2007). Participants rated the extent to which they currently felt like a burden on society and make things worse for the people in their life on a scale from 1 (not at all) to 7 (extremely). Mean scores were calculated with higher values indicating greater feelings of burdensomeness.

Negative COVID Experiences Adolescents were presented with a 20 -item $(\alpha=.75)$ checklist of statements about how they may have been negatively affected by COVID-19 in the past 7 days (e.g., state was on lockdown, self-quarantined, had family member lose a job). A sum score was calculated (possible range 0 to 20) with higher scores indicating greater negative COVID19 experiences.

Demographic Covariates Adolescents reported their age, gender, race, ethnicity, parents' education, and family financial strain. Highest level of mothers' and fathers' education were reported with separate items on a 3-point scale including 1 (high school or less), 2 (some college), and 3 (college graduate or more) with the option of indicating "I don't know" and were combined into one index representing 1 (neither parent attended college), 2 (at least one parent completed some college), and 3 (at least one parent completed college).

\section{Analytic Technique}

Multiple linear regression models were used to examine associations between adolescents' COVID-19 prosocial experiences (helping others, receiving help from others) and their mental health. Indicators of mental health (depressive symptoms, anxiety symptoms, burdensomeness, belonging) were specified as outcome variables and adolescents' engagement in COVID-19 prosocial behavior (i.e., giving help to others) and receipt of COVID-19 prosocial behavior were the primary predictor variables. Demographic characteristics (age, gender, race, ethnicity, parents' education, family financial strain), as well as a sum indicator of negative COVID-19 experiences, were included as covariates. Low levels of missing data $(<5 \%)$ were estimated using multiple imputation. Analyses were estimated using the $1 \mathrm{~m}$ function in $\mathrm{R}$ version 3.6.3 ( $\mathrm{R}$ Core Team, 2020).

\section{Results}

\section{Adolescents' Prosocial Experiences During COVID-19}

The frequencies for COVID-19 prosocial items are presented in Fig. 1. The percentage of adolescents who reported at least some engagement in prosocial acts aimed at helping others over the past seven days ranged from $23 \%$ to $90 \%$ across items. Adolescents most frequently endorsed giving support to friends, neighbors, or relatives who were worried about COVID-19, with $90 \%$ of youth providing support at least a little. The second most common prosocial behavior was giving a gift to quarantined friends or family. Helping with childcare and donating personal protective equipment were among the least frequently endorsed prosocial behaviors. Frequencies for endorsing at least some receipt of prosocial behavior by others over the past seven days ranged from $31 \%$ to $78 \%$, with receipt of support from friends, family, or neighbors the most frequently endorsed item. Receipt of money, food, or supplies was the least frequently endorsed item.

Means, standard deviations, and bivariate correlations among study variables are presented in Table 1. Engaging in COVID-19 prosocial behaviors and being the recipient of COVID-19 prosocial acts were moderately correlated. COVID-19 prosocial engagement was positively associated with indicators of mental health. Receipt of COVID19 prosocial acts by others was positively associated with anxiety symptoms and belongingness. Item-level correlations are available in the Supplemental Materials (Table S3). 
Table 1 Means, Standard Deviations, and Correlations for Study Variables

\begin{tabular}{|c|c|c|c|c|c|c|c|c|c|c|c|c|c|c|}
\hline Variable & $M / \%$ & $S D$ & 1 & 2 & 3 & 4 & 5 & 6 & 7 & 8 & 9 & 10 & 11 & 12 \\
\hline 1. Gender: female & $79.1 \%$ & - & & & & & & & & & & & & \\
\hline 2. Age & 16.43 & 1.10 & -.02 & & & & & & & & & & & \\
\hline 3. Race: White & $78.4 \%$ & - & .07 & $.12^{*}$ & & & & & & & & & & \\
\hline 4. Ethnicity: Hispanic & $15.2 \%$ & - & -.07 & .04 & $-.58 * *$ & & & & & & & & & \\
\hline 5. Financial Strain & 2.48 & 0.73 & -.05 & .04 & $-.14 * *$ & $.16^{* *}$ & & & & & & & & \\
\hline 6. Parent Education & 2.61 & 0.66 & -.00 & .00 & $.22 * *$ & $-.24 * *$ & $-.28 * *$ & & & & & & & \\
\hline 7. Negative COVID-19 Exp. & 9.61 & 3.29 & $.14 * *$ & .04 & .09 & -.05 & .04 & .01 & & & & & & \\
\hline 8. Actor in Prosocial Acts & 1.91 & 0.65 & .05 & -.04 & $.13^{* *}$ & -.06 & .06 & $.11^{*}$ & $.17 * *$ & & & & & \\
\hline 9. Recipient in Prosocial Acts & 1.93 & 0.71 & .09 & .02 & -.00 & -.01 & -.04 & .02 & .09 & $.39 * *$ & & & & \\
\hline 10. Depressive Symptoms & 3.39 & 1.00 & .05 & -.01 & $.11^{*}$ & -.03 & $.14 * *$ & -.06 & $.29 * *$ & $.10 *$ & -.09 & & & \\
\hline 11. Anxiety Symptoms & 3.10 & 1.09 & $.11^{*}$ & -.05 & .09 & -.06 & $.10^{*}$ & -.03 & $.30 * *$ & $* 21 * *$ & $.11 *$ & $.68 * *$ & & \\
\hline 12. Burdensomeness & 3.11 & 1.62 & .01 & -.07 & .02 & -.01 & $.14 * *$ & -.06 & $.13^{* *}$ & $.19 * *$ & -.02 & $.56^{* *}$ & $.45^{* *}$ & \\
\hline 13. Belonging & 3.90 & 1.40 & .03 & -.02 & -.02 & -.04 & $-.21 * *$ & .10 & -.06 & $.17 * *$ & $.33 * *$ & $-.45^{* *}$ & $-.22 * *$ & $-.32 * *$ \\
\hline
\end{tabular}

$M$ and $S D$ are used to represent mean and standard deviation, respectively. Negative COVID-19 Exp. = Negative COVID-19 Experiences

$*$ indicates $p<.05$. ** indicates $p<.01$

\section{Associations Between Prosocial Experiences and Mental Health}

Multiple regression models were used to examine associations between adolescents' COVID-19 prosocial experiences and mental health symptoms (see Table 2). When predicting depressive symptoms, greater negative COVID-19 experiences $(\beta=.27, p<.001)$ and greater family financial strain $(\beta=.10, p=.041)$ were associated with higher depressive symptoms. After accounting for demographic characteristics and negative COVID-19 experiences, being the recipient of COVID-19 prosocial acts more often was associated with lower depressive symptoms $(\beta=-.14, p=.006$; Fig. 2a). When predicting anxiety symptoms, greater negative COVID-19 experiences $(\beta=.27, p<.001)$ and engaging in COVID-19 prosocial acts more often $(\beta=.13, p=.009$; Fig. 3a) were each associated with greater anxiety symptoms. When predicting burdensomeness, greater engagement in COVID-19 prosocial behavior was associated with higher feelings of burdensomeness $(\beta=.21, p<.001$; Fig. 3b). For belongingness, greater negative COVID-19 experiences $(\beta=-.09, p=.044)$ and family financial strain $(\beta=-.20$, $p<.001)$ were associated with lower belongingness. After accounting for covariates, being the recipient of COVID-19 prosocial acts more often was associated with higher feelings of belonging ( $\beta=.30, p<.001$; Fig. $2 b)$.

\section{Discussion}

The COVID-19 pandemic presents a unique socio-historical moment that will likely have important consequences on adolescents' development. Although natural disasters have substantial negative effects on multiple domains of functioning (Weissbecker et al., 2008), collective crises also provide youth with opportunities for prosocial experiences (Bokszczanin, 2012). The purpose of this study was to examine adolescents' experiences regarding COVID-19 prosocial acts and investigate how these experiences were connected with their mental health. Based on relational developmental systems (RDS) metatheory (Overton, 2015) and altruism born of suffering (Staub \& Vollhardt, 2008; Vollhardt, 2009), we theorized that prosocial experiences may serve as ecological assets that help youth cope with the COVID-19 pandemic and would therefore be associated with better mental health. Findings demonstrate that many adolescents in the current sample were actors and recipients in a variety of COVID-19 prosocial acts (e.g., providing support to people concerned about the pandemic, making donations to charities or people in need, grocery shopping for individuals at risk, helping with household chores, and giving gifts). Connections between pandemic-related prosocial experiences and indicators of mental health were nuanced, as adolescents' COVID-19 prosocial experiences as the actor or recipient were differentially associated with anxiety symptoms, depressive symptoms, belongingness, and burdensomeness.

Consistent with hypotheses, being the recipient of prosocial action was associated with lower depressive symptoms and higher feelings of belongingness, suggesting pandemicrelated help may be an important ecological asset for beneficiaries in this context. Youth who are helped by others during times of crisis may be more inclined to feel connected with their peers and community and may be less inclined to experience negative moods. Feelings of gratitude are associated with greater emotional and social well-being (Froh et al., 2010). Being the recipient of prosocial actions during 


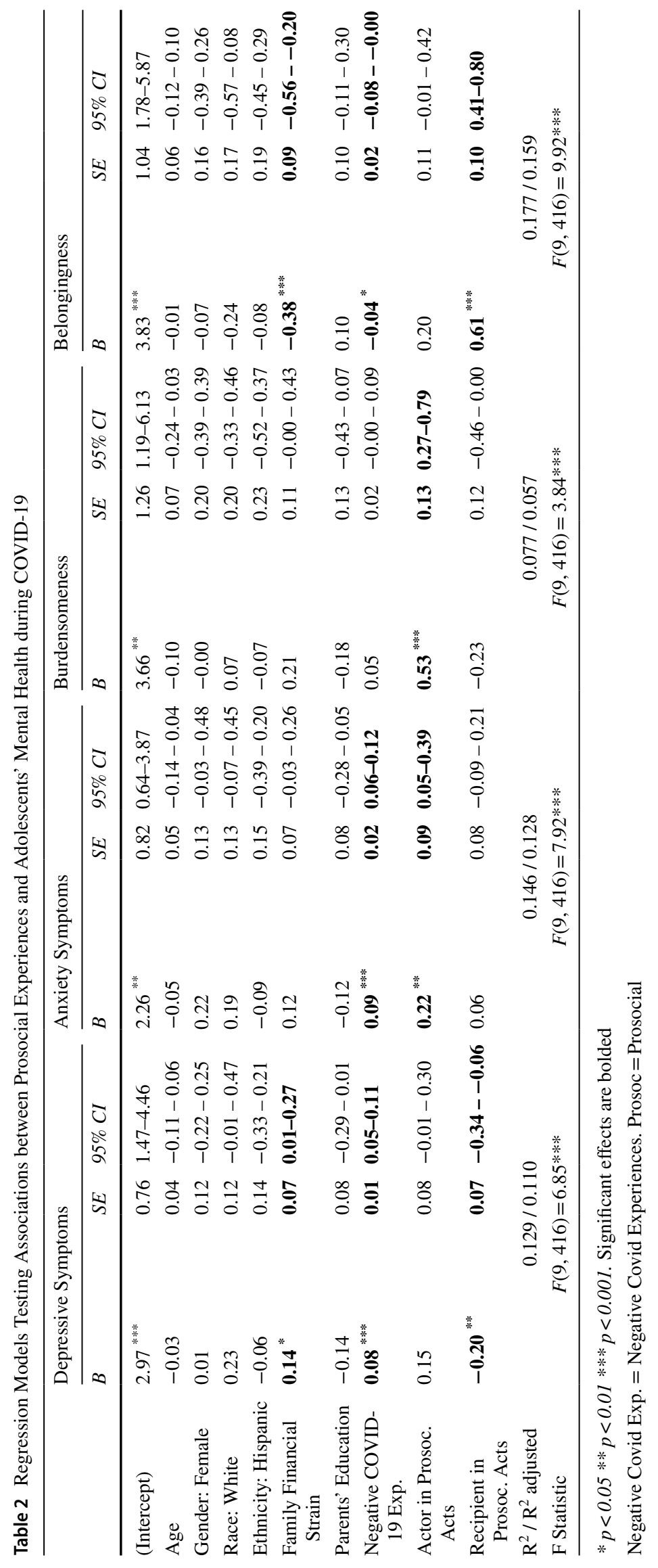



Receiving COVID-19 Prosocial Acts and Adolescent Mental Health
Fig. 2 Associations between
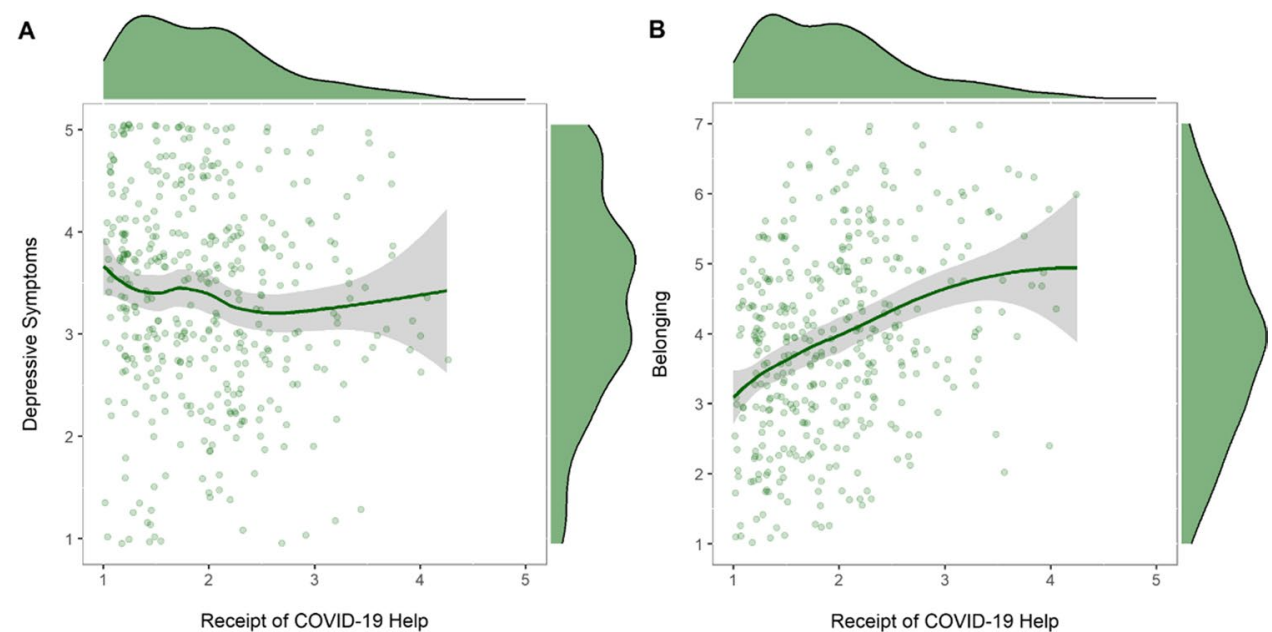

Fig. 3 Associations between Engagement in COVID-19 Prosocial Acts and Adolescent Mental Health
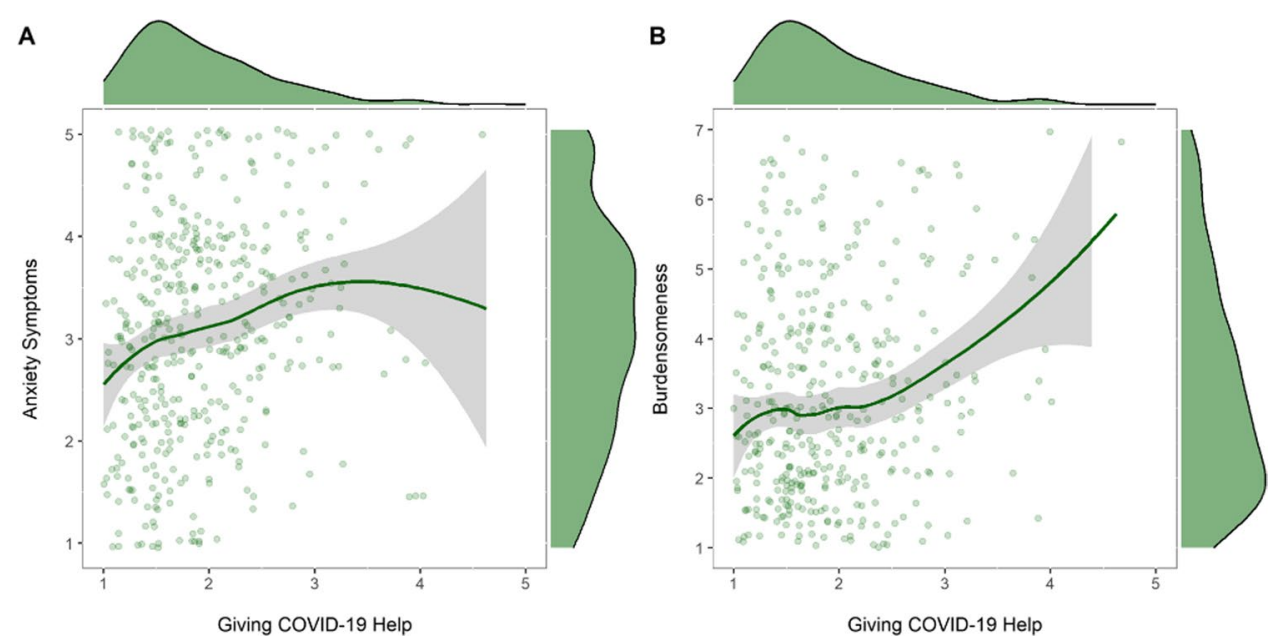

a collective trauma may provide a meaningful opportunity for these youth to practice gratitude, thereby promoting better mental and social health. Findings are consistent with previous studies that have found receipt of support is associated with a stronger sense of belonging (Hamm \& Faircloth, 2005) and can buffer against depression during times of crisis (e.g., HIV epidemic, McDowell \& Serovich, 2007; earthquake, Watanabe et al., 2004). It is also possible that youth who feel more connected and less depressed are more likely to receive help.

Contrary to hypotheses, engaging in COVID-19 prosocial behavior was associated with greater anxiety symptoms and feelings of burdensomeness. A potential motivation for engaging in prosocial behavior during a shared crisis may be to decrease one's own distress, as people may anticipate that helping others will distract them from their own stressful circumstances, provide meaning following the shared trauma, or help them regain a sense of control (Dovidio et al., 2017; Vollhardt \& Staub, 2011). Studies of vicarious victims of $9 / 11$ found that those who reported more postdisaster distress were more likely to help others (Piferi et al.,
2006; Wayment, 2004). In addition, a recent study on youth affected by severe earthquakes found that higher levels of post-disaster distress were associated with greater prosocial behavior toward other disaster survivors; the link was partially explained by increased connectedness with others who were similarly affected by the disaster (Vezzali et al., 2016). It is possible that adolescents who feel greater anxiety or burdensomeness during the COVID-19 pandemic sought out opportunities to help others with shared COVID-19 experiences as a means of alleviating or channeling these feelings into a productive outlet. It is also possible that participating in prosocial behavior during a pandemic-including supporting friends and family who are distressed-can promote anxiety and burdensomeness as youth are reminded of the global situation and impact that it is having on other people. Adolescents may perceive prosocial acts as an additional stressor during a collective trauma given their own disadvantage, limited psychological resources, and personal needs (Vollhardt \& Staub, 2011). This is consistent with research which suggests that too much commitment to others can be harmful to the self (Zahn-Waxler et al., 1991). These 
findings provide important nuance for how prosocial action may be connected to mental health during times of heightened stress.

Findings from this study have implications for public policy. Descriptively, our findings suggest a substantial proportion of adolescents in the current sample are engaged in COVID-19 prosocial behavior at least a little during a 7-day period. Parents, educators, clinicians, and policy makers seeking to improve adolescents' mental health during a collective crisis like the pandemic may benefit from encouraging youth to seek pandemic-related support and finding ways for youth to receive help from others, as being the recipient in COVID-19 prosocial acts may have positive implications for youth' mental health. Findings also highlight the potential importance of understanding how mental health may affect youths' prosocial action. Results showing youth with worse mental health engage in more COVID-19 prosocial acts may reflect a prosocial coping response to the pandemic, which has been associated with greater engagement in recommended and effective preventative health behaviors (e.g., wearing masks) during past pandemics (Lee-Baggley et al., 2004; Puterman et al., 2009). However, it is important for future research to further explore the potential for pandemic prosocial acts to harm youth and identify resources that may protect the mental health of youth who are more actively engaged in providing support to others during this heightened time of stress.

\section{Limitations}

The current study has several notable strengths, including the use a mixed-methods approach to develop a context-sensitive measure of prosocial experiences (i.e., behavior related to the COVID-19 pandemic), the inclusion of multiple indicators of adolescents' mental health, and the timeliness of providing data on adolescents' responses to the pandemic and related mental health in the early stages of the COVID19 pandemic. Findings should be also interpreted in the context of certain limitations. Data were correlational and crosssectional, so casual or temporal interpretations cannot be made. Future research is needed to examine within-person, longitudinal associations between prosocial experiences and mental health. Although we controlled for negative COVID19 experiences, future studies should examine the role of pre-pandemic exposure to adversity (e.g., economic hardship, racism, discrimination, early trauma), which put youth at risk for later mental health problems in response to stress (Wade et al., 2020). Although our sample was recruited from across the US, youth were primarily White and female and had higher levels of parent education relative to the US population of youth (NCES, 2021), which limits the generalizability of our findings. A large body of research evinces gender, race, and ethnicity differences in the prevalence and reporting of mental health symptoms (Kessler et al., 2009) and indicates that natural disasters have disproportionately adverse effects on the mental and physical health of marginalized groups, particularly Black Americans (Novacek et al., 2020; Pirtle, 2020; Purtle, 2012; Purtle, 2020). Moreover, it is unclear the extent to which our findings may generalize to other periods of the pandemic when our knowledge of the virus and government regulations and protocols began to shift. Future studies would benefit from examining prosocial experiences in a more sociodemographically diverse sample of youth at various points in time throughout the pandemic, which may yield a wider range of COVID-19 prosocial behaviors and negative COVID-19 experiences that our newly developed measures may not have captured. These future studies should also consider various pandemicrelated hardships (e.g., having a family member who is immunocompromised) and youths' employment and living situation (i.e., living at home with parents vs independently) as potential mediators or moderators of links between pandemic prosocial experiences and mental health. In addition, although inter-item total correlations were within acceptable range for items used to measure receipt of COVID-19 prosocial acts (Nunnally \& Bernstein, 1994), some itemtotal correlations were generally low. Future research should work to develop additional items that may strengthen our ability to reliably assess experiences receiving help during the pandemic. The validity of this newly developed measure of COVID-19 prosocial experiences should also be tested by examining multi-informant and observational reports of COVID-19 prosocial behavior and examine its relations to established measures of prosocial behavior and theoretically related constructs (e.g., perspective taking, moral reasoning, social responsibility values).

\section{Conclusions}

The current study highlights the importance of considering prosocial responses to the COVID-19 pandemic among adolescents. Our findings demonstrate that adolescents have opportunities to engage in and receive various forms of support and assistance during the COVID-19 pandemic. Prosocial interactions during this time of crisis may have important and nuanced implications for adolescents' mental health status and interpersonal needs, with findings cautioning that prosocial acts during a crisis may not be universally beneficial for adolescent actors and recipients. It will be important to further our understanding of these connections in youth to help inform post-disaster recovery and relief efforts.

Supplementary Information The online version contains supplementary material available at https://doi.org/10.1007/s12144-021-02670-y. 
Funding This study was funded by Center for American Indian and Rural Health Equity (CAIRHE).

Data availability The datasets generated during and/or analyzed during the current studyare available from the corresponding author on reasonable request.

\section{Declarations}

This study involved no more than minimal risk and thus, passive parental permission was used. All participants provided written informed assent.

Conflict of Interests The authors have no relevant financial or nonfinancial interests to disclose.

Ethical Approval This study was approved by the Institutional Review Board of the senior author's university.

\section{References}

Avdeyeva, T. V., Burgetova, K., \& Welch, I. D. (2006). To help or not to help? Factors that determined helping responses to Katrina victims. Analyses of Social Issues and Public Policy, 6(1), 159-173.

Bokszczanin, B. (2012). Social support provided by adolescents following a disaster and perceived social support, sense of community at school, and proactive coping. Anxiety, Stress \& Coping, 25(5), 575-592. https://doi.org/10.1080/10615806.2011.622374

Brooks, S. K., Webster, R. K., Smith, L. E., Woodland, L., Wessely, S., Greenberg, N., \& Rubin, G. J. (2020). The psychological impact of quarantine and how to reduce it: Rapid review of the evidence. The Lancet, 395, 912-920. https://doi.org/10.1016/ S0140-6736(20)30460-8

Cao, W., Fang, Z., Hou, G., Han, M., Xu, X., Dong, J., \& Zheng, J. (2020). The psychological impact of the COVID-19 epidemic on college students in China. Psychiatry Research, 287, 1-5. https:// doi.org/10.1016/j.psychres.2020.112934

Center for Disease Control and Prevention (2020). Cases in U.S. https:// www.cdc.gov/coronavirus/2019-ncov/cases-updates/cases-in-us. html. Accessed Apr 30, 2020.

Colarossi, L. G., \& Eccles, J. S. (2003). Differential effects of support providers on adolescents' mental health. Social Work Research, 27(1), 19-30.

Devi, A. T., Yusuf, M., \& Hardjono, H. (2017). The relationship between sense of community and agreeableness with prosocial behavior among member of young on top (YOT). Journal of ICSAR, I(1), 6-12.

Dodd, C. G., Hill, R. M., Oosterhoff, B., \& Layne, C. M. (2019). The hurricane exposure, adversity, and recovery tool (HEART): Developing and validating a risk screening instrument for youth exposed to hurricane Harvey. Journal of Family Strengths, 19(1), 1-26.

Dovidio, J. F., Piliavin, J. A., Schroeder, D. A., \& Penner, L. A. (2017). The social psychology of prosocial behavior. Psychology Press.

Eccles, J. S., \& Gootman, J. A. (Eds.). (2002). Community programs to promote youth development. Washington, DC: National Academy Press.

Froh, J. J., Bono, G., \& Emmons, R. (2010). Being grateful is beyond good manners: Gratitude and motivation to contribute to society among early adolescents. Motivation and Emotion, 34(2), $144-157$.

Furman, W., \& Buhrmester, D. (1985). Children's perceptions of the personal relationships in their social networks. Developmental Psychology, 21(6), 1016-1024.
Gagné, M. (2003). The role of autonomy support and autonomy orientation in prosocial behavior engagement. Motivation and Emotion, 27(3), 199-223.

Galinsky, E. (1999). Ask the children: What America's children really think about working parents. William Morrow and Company.

Gordon, K. H., Bresin, K., Dombeck, J., Routledge, C., \& Wonderlich, J. A. (2011). The impact of the 2009 Red River Flood on interpersonal risk factors for suicide. Crisis, 32(1), 52-55. https://doi.org/ 10.1027/0227-5910/a000051

Hamm, J., \& Faircloth, B. (2005). The role of friendship in adolescents' sense of school belonging. New Directions for Child and Adolescent Development, 107, 61-78. https://doi.org/10.1002/cd.121

Haroz, E. E., Murray, L. K., Bolton, P., Betancourt, T., \& Bass, J. K. (2013). Adolescent resilience in northern Uganda: The role of social support and prosocial behavior in reducing mental health problems. Journal of Research on Adolescence, 23(1), 138-148.

Joiner, T. (2007). Why people die by suicide. Harvard University Press.

Joiner Jr., T. E., Pettit, J. W., Walker, R. L., Voelz, Z. R., Cruz, J., Rudd, M. D., \& Lester, D. (2002). Perceived burdensomeness and suicidality: Two studies on the suicide notes of those attempting and those completing suicide. Journal of Social \& Clinical Psychology, 21, 531-545. https://doi.org/10.1521/jscp.21.5.531.22624

Kahana, B., Harel, Z., \& Kahana, E. (1988). Predictors of psychological well-being among survivors of the Holocaust. In J. P. Wilson, Z. Harel, \& B. Kohana (Eds.), Human adaptation to extreme stress (pp. 171-192). Boston: Springer.

Kaniasty, K. (2012). Predicting social psychological well-being following trauma: The role of postdisaster social support. Psychological Trauma: theory, research, practice, and policy, 4(1), 22-33. https://doi.org/10.1037/a0021412

Kaniasty, K., \& Norris, F. H. (2004). Social support in the aftermath of disasters, catastrophes, and acts of terrorism: Altruistic, overwhelmed, uncertain, antagonistic, and patriotic communities. In R. J. Ursano, A. E. Norwood, \& C. S. Fullerton (Eds.), Bioterrorism: Psychological and public health interventions (pp. 200-229). Cambridge University Press.

Kaniasty, K., \& Norris, F. (2009). Distinctions that matter: Received social support, perceived social support, and social embeddedness after disasters. In Y. Neria, S. Galea, \& F. Norris (Eds.), Mental health and disasters (pp. 175-200). Cambridge University Press.

Kennedy, R., Clifford, S., Burleigh, T., Waggoner, P. D., Jewell, R., $\&$ Winter, N. J. (2018). The shape of and solutions to the MTurk quality crisis. Political Science Research and Methods, 1-16. https://doi.org/10.1017/psrm.2020.6

Kerr, D. C., Preuss, L. J., \& King, C. A. (2006). Suicidal adolescents' social support from family and peers: Gender-specific associations with psychopathology. Journal of Abnormal Child Psychology, 34, 103-114.

Kessler, R. C., Aguilar-Gaxiola, S., Alonso, J., Chatterji, S., Lee, S. Ormel, J., et al. (2009). The global burden of mental disorders: An update from the WHO world mental health (WMH) surveys. Epidemiology and Psychiatric Sciences, 18(1), 23-33.

LaGreca, A. M., \& Lopez, N. (1998). Social anxiety among adolescents: Linkages with peer relations and friendships. Journal of Abnormal Child Psychology, 26, 83-94.

Lee, F. H., Heimer, H., Giedd, J. N., Lein, E. S., Weinberger, D. R., \& Casey, B. J. (2014). Adolescent mental health-Opportunity and obligation. Science Magazine, 346(6209), 547-549.

Lee-Baggley, D., DeLongis, A., Voorhoeave, P., \& Greenglass, E. (2004). Coping with the threat of severe acute respiratory syndrome: Role of threat appraisals and coping responses in health behaviors. Asian Journal of Social Psychology, 7(1), 9-23.

Ludvigsson, J. F. (2020). Systematic review of COVID-19 in children shows milder cases and a better prognosis than adults. Acta Paediatrica, 109(6), 1088-1095. 
McDowell, T. L., \& Serovich, J. M. (2007). The effect of perceived and actual social support on the mental health of HIV-positive persons. AIDS Care, 19(10), 1223-1229. https://doi.org/10.1080/ 09540120701402830

Merikangas, K. R., He, J. P., Burstein, M., Swanson, S. A., Avenevoli, S., Cui, L., et al. (2010). Lifetime prevalence of mental disorders in US adolescents: Results from the National Comorbidity Survey Replication-Adolescent Supplement (NCS-A). Journal of the American Academy of Child \& Adolescent Psychiatry, 49(10), 980-989.

Nantel-Vivier, A., Pihl, R. O., Côté, S., \& Tremblay, R. E. (2014). Developmental association of prosocial behaviour with aggression, anxiety and depression from infancy to preadolescence. Journal of Child Psychology and Psychiatry, 55(10), 1135-1144.

National Center for Education Statistics (NCES). (2021). Characteristics of Children's Families. Annual Reports and Information Staff (Annual Reports). Retrieved November 14, 2021, from https:// nces.ed.gov/programs/coe/indicator/cce

Novacek, D. M., Hampton-Anderson, J. N., Ebor, M. T., Loeb, T. B., \& Wyatt, G. E. (2020). Mental health ramifications of the COVID-19 pandemic for black Americans: Clinical and research recommendations. Psychological Trauma: Theory, Research, Practice, and Policy, 12(5), 449-451. https://doi.org/10.1037/tra0000796449

Nunnally, J. C., \& Bernstein, I. H. (1994). The assessment of reliability. Psychometric Theory, 3, 248-292.

Oosterhoff, B., \& Palmer, C. (2020). Psychological correlates of news monitoring, social Distancing, disinfecting, and hoarding behaviors among US adolescents during the COVID-19 pandemic. https://doi.org/10.31234/osf.io/rpcy4

Oosterhoff, B., Hill, R. M., \& Slonaker, N. (2019). Longitudinal associations between civic engagement and interpersonal needs among college students during the 2018 US midterm elections. https:// doi.org/10.31234/osf.io/5xedv

Oosterhoff, B., Poppler, A., Hill, R.M., Fitzgerald, H., \& Shook, N.J. (2021). Understanding the costs and benefits of politics among adolescents within a sociocultural context. Infant and Child Development: Prenatal, childhood, adolescence, emerging adulthood.

Overton, W. F. (2015). Process and relational developmental systems. In W. F. Overton, \& P. C. Molenaar (Eds.), Handbook of child psychology and developmental science. Vol. 1: Theory and method (7th ed.)

Penner, L. A., Dovidio, J. F., Piliavin, J. A., \& Schroeder, D. A. (2005). Prosocial behavior: Multilevel perspectives. Annual Review of Psychology, 56, 365-392. https://doi.org/10.1146/annurev.psych. 56.091103 .070141

Piferi, R. L., Jobe, R. L., \& Jones, W. H. (2006). Giving to others during national tragedy: The effects of altruistic and egoistic motivations on long-term giving. Journal of Social and Personal Relationships, 23(1), 171-184

Pirtle, W. N. L. (2020). Racial capitalism: A fundamental cause of novel coronavirus (COVID-19) pandemic inequities in the United States. Health Education \& Behavior, 47(4), 504-508. https://doi. org/10.1177/1090198120922942

Purtle, J. (2012). Racial and ethnic disparities in post-disaster mental health: Examining the evidence through a lens of social justice. Washington and Lee Journal of Civil Rights and Social Justice, 19, 32-53. https://scholarlycommons.law.wlu.edu/crsj/vol19/ iss $1 / 7$. Accessed July 2020.

Purtle, J. (2020). COVID-19 and mental health equity in the United States. Social Psychiatry and Psychiatric Epidemiology, 55(8), 969-971. https://doi.org/10.1007/s00127-020-01896-8

Puterman, E., Delongis, A., Lee-Baggley, D., \& Greenglass, E. (2009). Coping and health behaviours in times of global health crises: Lessons from SARS and West Nile. Global Public Health, 4(1), 69-81.

Quinn, H., Thissen, D., Liu, Y., et al. (2014). Using item response theory to enrich and expand the PROMIS $®$ pediatric self-report banks. Health and Quality of Life Outcomes, 12(60), 1-10. https:// doi.org/10.1186/s12955-014-0160-x
R Core Team (2020). R: A language and environment for statistical computing. R Foundation for statistical Computing, Vienna, Austria. http://www.R-project.org/

Reissman, D. B., Watson, P. J., Klomp, R. W., Tanielian, T. L., \& Prior, S. D. (2006). Pandemic influenza preparedness: Adaptive responses to an evolving change. Journal of Homeland Security and Emergency Management, 3(2), 1-26.

Rodriguez, H., Trainor, J., \& Quarantelli, E. L. (2006). Rising to the challenges of a catastrophe: The emergent and prosocial behavior following hurricane Katrina. The Annals of the American Academy of Political and Social Science, 604(1), 82-101.

Schwartz, C. E., Meisenhelder, J. B., Yusheng, A., \& Reed, G. (2003). Altruistic social interest behaviors are associated with better mental health. Psychosomatic Medicine, 65, 778-785.

Shakespeare-Finch, J. E., \& Green, J. (2013). Social support promotes psychological well-being following a natural disaster. In Australia \& New Zealand Disaster \& Emergency Management Conference (pp. 210-229). AST Management Pty Ltd.

Shang, F., Kaniasty, K., Cowlishaw, S., Wade, D., Ma, H., \& Forbes, D. (2019). Social support following a natural disaster: A longitudinal study of survivors of the 2013 Lushan earthquake in China. Psychiatry Research, 273, 641-646. https://doi.org/10.1016/j.psych res.2019.01.085

Smetana, J. G., Campione-Barr, N., \& Metzger, A. (2006). Adolescent development in interpersonal and societal contexts. Annual Review of Psychology, 57, 255-284. https://doi.org/10.1146/annur ev.psych.57.102904.190124

Spear, L. (2010). The behavioral neuroscience of adolescence. WW Norton \& Company.

Vergin, J. (2020). Solidarity: How the coronavirus makes us more willing to help. https://p.dw.com/p/3aFYn. Accessed June 2020.

Vezzali, L., Drury, J., Versari, A., \& Cadamuro, A. (2016). Sharing distress increases helping and contact intentions via social identification and inclusion of the other in the self: Children's prosocial behavior after an earthquake. Group Processes \& Intergroup Relations, 19(3), 314-327.

Vollhardt, J. R. (2009). Altruism born of suffering and prosocial behavior following adverse life events: A review and conceptualization. Social Justice Research, 22(1), 53-97.

Vollhardt, J. R., \& Staub, E. (2011). Inclusive altruism born of suffering: The relationship between adversity and prosocial attitudes and behavior toward disadvantaged outgroups. American Journal of Orthopsychiatry, 81(3), 307-315. https://doi.org/10.1111/j. 1939-0025.2011.01099.x

Wade, M., Prime, H., \& Browne, D. T. (2020). Why we need longitudinal mental health research with children and youth during (and after) the COVID-19 pandemic. Psychiatry Research, 290, 113143. https://doi.org/10.1016/j.psychres.2020.113143

Wang, C., Pan, R., Wan, X., Tan, Y., Xu, L., Ho, C. S., \& Ho, R. C. (2020). Immediate psychological responses and associated factors during the initial stage of the 2019 coronavirus disease (COVID19) epidemic among the general population in China. International Journal of Environmental Research and Public Health, 17(5), 1-25. https://doi.org/10.3390/ijerph17051729

Watanabe, C., Okumura, J., Chiu, T.-Y., \& Wakai, S. (2004). Social support and depressive symptoms among displaced older adults following the 1999 Taiwan earthquake. Journal of Traumatic Stress, 17(1), 63-67. https://doi.org/10.1023/B:JOTS.00000 14678.79875

Watson, G. (2020). If we're all caught in a dangerous pandemic, where does the impulse to help others come from?. Washington Post. https://www.washingtonpost.com/lifestyle/wellness/if-wereall-caught-in-a-dangerous-pandemic-where-does-the-impulse-tohelp-others-come-from/2020/04/01/c9f0f34c-7382-11ea-a9bd9f8b593300d0_story.html. Accessed June 2020. 
Wayment, H. A. (2004). It could have been me: Vicarious victims and disaster-focused distress. Personality and Social Psychology Bulletin, 30(4), 515-528.

Weinstein, N., \& Ryan, R. M. (2010). When helping helps: Autonomous motivation for prosocial behavior and its influence on well-being for the helper and recipient. Journal of Personality and Social Psychology, 98(2), 222-244. https://doi.org/10.1037/a0016984

Weissbecker, I., Sephton, S. E., Martin, M. B., \& Simpson, D. M. (2008). Psychological and physiological correlates of stress in children exposed to disaster: Current research and recommendations for intervention. Children Youth and Environments, 18(1), 30-70.

World Health Organization. (2020). Coronavirus disease 2019 (COVID-19) situation report - 87. https://www.who.int/docs/ default-source/coronaviruse/situation-reports/20200416-sitrep87-covid-19.pdf?sfvrsn=9523115a_2. Accessed Apr 30, 2020.

Xie, X., Xue, Q., Zhou, Y., Zhu, K., Liu, Q., Zhang, J., \& Song, R. (2020). Mental health status among children in home confinement during the coronavirus disease 2019 outbreak in Hubei Province, China. JAMA Pediatrics, 174(9), 898-900. https://doi.org/10. 1001/jamapediatrics.2020.1619
Yentes, R. D., \& Wilhelm, F. (2018). Careless: Procedures for computing indices of careless responding. (Version 1.1.3) [Computer software].

Youniss, J., \& Yates, M. (1997). Community service and social responsibility in youth. University of Chicago Press.

Zahn-Waxler, C., Cole, P. M., \& Barrett, K. C. (1991). Guilt and empathy: Sex differences and implications for the development of depression. In J. Garber \& K. A. Dodge (Eds.), Cambridge studies in social and emotional development. The development of emotion regulation and dysregulation (pp. 243-272). Cambridge University Press. https://doi.org/10.1017/CBO9780511663963.012

Zhou, S. J., Zhang, L. G., Wang, L. L., Guo, Z. C., Wang, J. Q., Chen, J. C., et al. (2020). Prevalence and socio-demographic correlates of psychological health problems in Chinese adolescents during the outbreak of COVID-19. European Child \& Adolescent Psychiatry, 29, 749-758. https://doi.org/10.1007/s00787-020-01541-4

Publisher's note Springer Nature remains neutral with regard to jurisdictional claims in published maps and institutional affiliations. 